\title{
Two-Stage Control Design of a Buck Converter/DC Motor System without Velocity Measurements via a $\Sigma-\Delta$-Modulator
}

\author{
R. Silva-Ortigoza, ${ }^{1}$ J. R. García-Sánchez, ${ }^{1}$ J. M. Alba-Martínez, ${ }^{1}$ V. M. Hernández-Guzmán, \\ M. Marcelino-Aranda, ${ }^{3}$ H. Taud, ${ }^{1}$ and R. Bautista-Quintero ${ }^{4}$ \\ ${ }^{1}$ Instituto Politécnico Nacional, CIDETEC, Área de Mecatrónica, Unidad Profesional Adolfo López Mateos, \\ 07700 México, DF, Mexico \\ ${ }^{2}$ Universidad Autónoma de Querétaro, Facultad de Ingeniería, 76150 Querétaro, QRO, Mexico \\ ${ }^{3}$ Instituto Politécnico Nacional, UPIICSA, Sección de Estudios de Posgrado e Investigación, 08400 México, DF, Mexico \\ ${ }^{4}$ Instituto Tecnológico de Culiacán, Departamento de Metal-Mecánica, 80220 Culiacán, SIN, Mexico
}

Correspondence should be addressed to R. Silva-Ortigoza; rsilvao@ipn.mx

Received 14 February 2013; Accepted 7 April 2013

Academic Editor: Ebrahim Momoniat

Copyright (c) 2013 R. Silva-Ortigoza et al. This is an open access article distributed under the Creative Commons Attribution License, which permits unrestricted use, distribution, and reproduction in any medium, provided the original work is properly cited.

\begin{abstract}
This paper presents a two-stage control design for the "Buck power converter/DC motor" system, which allows to perform the sensorless angular velocity trajectory tracking task. The differential flatness property of the DC-motor model is exploited in order to propose a first-stage controller, which is designed to achieve the desired angular velocity trajectory. This controller provides the voltage profiles that must be tracked by the Buck converter. Then, a second-stage controller is meant to assure the aforementioned. This controller is based on flatness property of the Buck power converter model, which provides the input voltage to the DC motor. Due to the fact that the two-stage controller proposed uses the average model of the system, as a practical and effective implementation of this controller, a $\Sigma-\Delta$-modulator is employed. Finally, in order to verify the control performance of this approach, numerical simulations are included.
\end{abstract}

\section{Introduction}

In the market of electric servo motor drivers, the most common technology-used in robotics and electric vehicles-is based on solid-state devices. For both velocity and position control purposes, these solid-state servo drives require a power electronic converter which is used as an interface between the input power line and the motor [1]. One of the most common topologies is the Buck-switched DC/DC power converter. Due to the fact that Buck converter contains two energy-storing elements (an inductance and a capacitor), smooth DC output voltages and currents with very small current ripple are generated. In order to obtain-at any time-a high power conversion rate, when angular velocity control is required, the converter design is very important.

Previously in the literature, different proposals have explored the combination of several topologies of DC/DC power converters with DC motors. This work is particularly focused on the velocity control of a DC Motor based on regulating the output voltage of a Buck DC/DC power converter.

In 2000, Lyshevski [2] proposed fourth-order mathematical models for coupled systems of both power electronic converters and a permanent magnet DC motor. Furthermore, Lyshevski shows a control design based on PI strategy which is meant to regulate angular velocity for the DC motor.

In contrast to previous works, in 2004 Linares-Flores and Sira-Ramírez presented in [3-5] the design of smooth angular velocity control for DC motor powered by a DC/DC Buck converter. This approach was validated by numerical simulations.

In [3] a differential flatness control approach was presented, where a second-order model is employed based on neglecting both armature inductance and the current that 


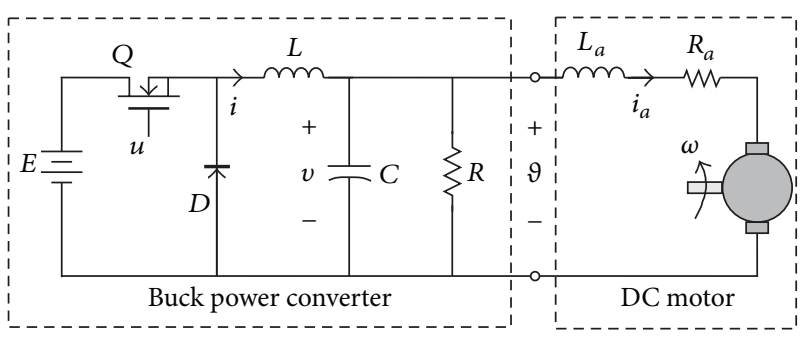

FIGURE 1: DC motor driven by a DC/DC Buck power converter.

flows through capacitor of the converter; according to [6], this approximation is not convenient for low- and mediumpower applications. Based on the second-order model presented in [3, 4], a GPI average control is introduced; this strategy requires motor shaft angular measurements and its implementation uses a $\Sigma-\Delta$-modulator. In [5] based on the fourth-order model of this system (described previously in [2]) was presented the design of a dynamic output feedback controller via the Energy Shaping and Damping Injection method (see Ortega et al. [7]).

In 2006, Linares-Flores in [8] (partially published in [9]) and Antritter et al. in [10] presented an angular velocity control based on differential flatness applying a fourth-order model of a DC motor powered by a Buck DC-DC converter [2]. Control performance is not evaluated experimentally when parametric uncertainties are present in the system. Also in 2006, Fadil and Giri [6] proposed the design of both adaptive and nonadaptive controllers based on backstepping. This work shows by numerical simulations that the adaptive version has good performance against rapid changes of the setpoint and load torque. Additionally, neither smooth transition changes nor system parameters uncertainties are considered.

A comparative evaluation of control performance through numerical simulations of several control strategies, such as PI, PI + Fuzzy Logic, and LQR, for angular velocity trajectory tracking of a DC motor powered by a Buck converter was presented by Ahmad et al. [11] in 2010. Similarly in 2011, Sureshkumar and Ganeshkumar in [12] via numerical simulations compared the performance of both PI and backstepping controllers related to angular velocity regulation of the aforementioned system.

More recently, in 2013 Sira-Ramírez and Oliver-Salazar [13] proposed a robust control based on an active disturbance rejection control and differential flatness, considering the presence of unknown time-varying load, for two different combinations of Buck power converters and DC motors. Numerical simulations showed the robustness of this technique for the angular velocity control of the motor shaft.

Finally, angular velocity control related to cascade configurations for other DC/DC topologies of power electronic converters with DC motors has been reported in $[8,14,15]$.

Regarding "DC/DC Buck power converter-DC motor," the combined system model has been addressed in two fashions: (1) by using a fourth-order model that leads to very long control laws, (2) by using a second-order model, that neglects either parameters or states of the system which is not always a convenient simplification [6]. In this paper, a variation from fashion (1), both motor and converter models are considered separately.

Based on the literature review introduced previously, the control performance for the regulation and trajectory tracking tasks is not studied for uncertainties associated neither converter parameters, nor motor parameters nor large changes of their nominal values. In contrast, this work includes such uncertainties and large value changes in order to show the effectiveness for practical applications.

Motivated for multiple stage control approach used in mobile robots [16-18], the equation that governs the highlevel-stage control imposes the desired trajectory to be followed, for a low-level-stage control, through an inner controlloop. In this paper, a two-stage control is proposed for the "Buck power converter-DC motor" which is designed for the sensorless angular velocity trajectory tracking control. This control is achieved by using integral reconstructors $[19,20]$. Furthermore, since the two-stage control approach proposed is based on the system average model, which is not suitable for implementation of the power transistor commutation (core of the Buck converter), it uses a $\Sigma-\Delta$-modulator implementation of a sliding mode controller for the average feedback controller design in a rather efficient manner, as discussed in $[21,22]$. Control performance is validated via numerical simulations.

The remaining of the paper is organized as follows. Section 2 presents the design of the control laws, likewise its connections in order to obtain a two-stage control of the "Buck power converter-DC motor." Evaluation of the twostage control performance is presented in Section 3, based on realistic simulations of the close-loop system; they are programmed in MATLAB/Simulink. Finally, conclusions are given in Section 4.

\section{Two-Stage Controller for the Buck Power Converter-DC Motor}

This section shows the design of the two-stage controller for the "Buck power converter-DC motor" for the angular velocity trajectory tracking task. The system to be controlled is shown in Figure 1.

Two controllers are proposed separately, the first-stage for the DC motor and the second-stage for the Buck power converter. After that, by using a two-stage controller, similar to the approaches presented in $[16,17]$, both stages are connected in order to get the goal; that is,

(1) DC motor control based on differential-flatness is developed in $[23,24]$, which allows the angular velocity trajectory tracking task. This control requires position, velocity, and acceleration measurements which are generally obtained from electromechanic sensors. Alternatively, by using integral reconstructors (see $[19,20]$ ), electromechanic measurements are no longer needed; electric measurements replace them.

(2) The control developed in (1) provides a voltage profile, $\vartheta$, that must be tracked by the output voltage of the 
Buck power converter, $v$. Then, to this end, another control based on differential flatness is developed for the converter, which is implemented with the $\Sigma-\Delta$ modulator, as discussed in [21, 22].

(3) Finally, through the two-stage control approach, the controllers aforementioned in (1) and (2) are interconnected to provide a solution to the angular velocity trajectory tracking task.

2.1. Sensorless Velocity Control of a DC Motor. Following $[17,23-25]$, this subsection presents a control approach based on differential flatness and integral reconstructors for a DC motor. A mathematical model is expressed in terms of the motor shaft angular velocity $\omega,[24]$ :

$$
\begin{gathered}
L_{a} \frac{d i_{a}}{d t}=\vartheta-R_{a} i_{a}-n k_{e} \omega, \\
J \frac{d \omega}{d t}=-b \omega+n k_{m} i_{a},
\end{gathered}
$$

where $\vartheta$ is the motor armature voltage, $i_{a}$ is the armature current, $k_{e}$ is the constant due to the counterelectromotive force, $k_{m}$ is the constant of the motor torque, $L_{a}$ is the armature inductance, $R_{a}$ is the armature resistance, $J$ is the rotor and load inertia, $b$ is the viscous friction coefficient due to both motor and load, and $n$ represents the gearbox reduction ratio.

Matrix representation of systems (1)-(2) is determined by the following

$$
\begin{gathered}
\dot{\chi}=\mathscr{A} \chi+\mathscr{B} \vartheta \\
y_{1}=\mathscr{C} \chi,
\end{gathered}
$$

where $\chi=\left(i_{a} \quad \omega\right)^{T}$ and

$$
\mathscr{A}=\left(\begin{array}{cc}
-\frac{R_{a}}{L_{a}} & -\frac{n k_{e}}{L_{a}} \\
\frac{n k_{m}^{a}}{J} & -\frac{b}{J}
\end{array}\right) ; \quad \mathscr{B}=\left(\begin{array}{c}
\frac{1}{L_{a}} \\
0
\end{array}\right) ; \quad \mathscr{C}=\left(\begin{array}{l}
0 \\
1
\end{array}\right)^{T} .
$$

Controllability matrix of system (3) is given by the following:

$$
\mathbf{C}_{1}=\left(\begin{array}{ll}
\mathscr{B} & \mathscr{A} \mathscr{B}
\end{array}\right)=\left(\begin{array}{cc}
\frac{1}{L_{a}} & -\frac{R_{a}}{L_{a}^{2}} \\
0 & \frac{n k_{m}}{J L_{a}}
\end{array}\right)
$$

due to

$$
\operatorname{det} \mathbf{C}_{1}=\frac{n k_{m}}{J L_{a}^{2}} \neq 0
$$

then the system is controllable. According to [24], the flat output is obtained by multiplying the last row of the inverse controllability matrix by the state vector, that is,

$$
\left(\begin{array}{ll}
0 & 1
\end{array}\right) \mathbf{C}_{1}^{-1} \chi=\frac{J L_{a}}{n k_{m}} \omega
$$

Without loss of generality, the angular velocity is considered as a flat output, that is,

$$
F_{1}=\omega
$$

Thus, from (1) and (2), variables of the system $\chi$ and the control input $\vartheta$ can be written, in terms of $F_{1}$ and its derivatives, as follows:

$$
\begin{gathered}
\omega=F_{1}, \\
i_{a}=\frac{1}{n k_{m}}\left(J \dot{F}_{1}+b F_{1}\right), \\
\vartheta=\frac{J L_{a}}{n k_{m}} \ddot{F}_{1}+\frac{1}{n k_{m}}\left(b L_{a}+J R_{a}\right) \dot{F}_{1}+\left(\frac{b R_{a}}{n k_{m}}+n k_{e}\right) F_{1} .
\end{gathered}
$$

From (11), if the motor control is taken as follows:

$$
\vartheta=\frac{J L_{a}}{n k_{m}} \mu_{m}+\frac{1}{n k_{m}}\left(b L_{a}+J R_{a}\right) \dot{F}_{1}+\left(\frac{b R_{a}}{n k_{m}}+n k_{e}\right) F_{1},
$$

then the trajectory tracking control problem of the flat output is simplified to control the system as follows:

$$
\ddot{F}_{1}=\mu_{m}
$$

If $F_{1}^{*}$ is the desired angular velocity trajectory, $\mu_{m}$ must be chosen such that $F_{1} \rightarrow F_{1}^{*}$ when $t \rightarrow \infty$. A practical choice of $\mu_{m}$ that achieves this task is given by the following:

$$
\mu_{m}=\ddot{F}_{1}^{*}-\gamma_{2}\left[\dot{F}_{1}-\dot{F}_{1}^{*}\right]-\gamma_{1}\left[F_{1}-F_{1}^{*}\right]-\gamma_{0} \int_{0}^{t}\left[F_{1}-F_{1}^{*}\right] d \tau .
$$

If error is defined as $e=F_{1}-F_{1}^{*}$, the close-loop dynamic error is found by substituting (14) into (13), and by deriving the integro-differential expression, we obtain the following:

$$
\dddot{e}+\gamma_{2} \ddot{e}+\gamma_{1} \dot{e}+\gamma_{0} e=0,
$$

whose polynomial characteristic is as follows:

$$
p_{1}(s)=s^{3}+\gamma_{2} s^{2}+\gamma_{1} s+\gamma_{0}
$$

Thus, in order to get that $e \rightarrow 0$ when $t \rightarrow \infty$, that is, $F_{1} \rightarrow$ $F_{1}^{*}$, it is required that $p_{1}(s)$ be a Hurwitz polynomial. Based on the following Hurwitz polynomial:

$$
p_{1 d}(s)=\left(s+a_{1}\right)\left(s^{2}+2 \zeta_{1} \omega_{n 1} s+\omega_{n 1}^{2}\right),
$$

by equating (16) with (17), it is found that parameters $\gamma_{2}, \gamma_{1}$, and $\gamma_{0}$ are given by the following:

$$
\gamma_{2}=a_{1}+2 \zeta_{1} \omega_{n 1} ; \quad \gamma_{1}=2 \zeta_{1} \omega_{n 1} a_{1}+\omega_{n 1}^{2} ; \quad \gamma_{0}=a_{1} \omega_{n 1}^{2}
$$

If an implementation of the controllers (12)-(14) were required, the position, velocity, and acceleration must be measured (which generally are provided by electromechanic sensors). Then, an alternatively sensorless control design by means of integral reconstructor of $\omega$ and $\dot{\omega}$ is presented. 
Integrating (1), the following is obtained:

$$
\begin{gathered}
\int_{0}^{t} \omega d \tau=\widehat{\int_{0}^{t} \omega d \tau}+\frac{L_{a}}{n k_{e}} i_{a}(0), \\
\widetilde{\int_{0}^{t} \omega d \tau}=\frac{L_{a}}{n k_{e}}\left[-i_{a}+\frac{1}{L_{a}} \int_{0}^{t}\left(\vartheta-R_{a} i_{a}\right) d \tau\right] .
\end{gathered}
$$

On the other hand, integrating (2) and using (19), the following is obtained:

$$
\begin{gathered}
\omega=\widehat{\omega}+\omega(0)-\frac{b L_{a}}{n J k_{e}} i_{a}(0), \\
\widehat{\omega}=-\frac{b}{J}\left[\frac{L_{a}}{n k_{e}}\left[-i_{a}+\frac{1}{L_{a}} \int_{0}^{t}\left(\vartheta-R_{a} i_{a}\right) d \tau\right]-\frac{n k_{m}}{b} \int_{0}^{t} i_{a} d \tau\right] .
\end{gathered}
$$

Finally, substituting (21) into (2), the following is obtained:

$$
\begin{gathered}
\dot{\omega}=\widehat{\dot{\omega}}-\frac{b}{J} \omega(0)+\frac{b^{2} L_{a}}{n J^{2} k_{e}} i_{a}(0) \\
\hat{\dot{\omega}}=\frac{b^{2}}{J^{2}}\left[\frac{L_{a}}{n k_{e}}\left[-i_{a}+\frac{1}{L_{a}} \int_{0}^{t}\left(\vartheta-R_{a} i_{a}\right) d \tau\right]-\frac{n k_{m}}{b} \int_{0}^{t} i_{a} d \tau\right] \\
+\frac{n k_{m}}{J} i_{a} .
\end{gathered}
$$

It is proposed to use the following modified control law, alternatively to (12) and (14):

$$
\begin{aligned}
\vartheta=\frac{J L_{a}}{n k_{m}} \mu_{m} & +\frac{1}{n k_{m}}\left(b L_{a}+J R_{a}\right) \hat{\dot{\omega}}+\left(\frac{b R_{a}}{n k_{m}}+n k_{e}\right) \widehat{\omega}, \\
\mu_{m}= & \ddot{\omega}^{*}(t)-\gamma_{2}\left(\widehat{\hat{\omega}}-\dot{\omega}^{*}\right)-\gamma_{1}\left(\widehat{\omega}-\omega^{*}\right) \\
& -\gamma_{0}\left(\widehat{\int_{0}^{t} \omega d \tau}-\int_{0}^{t} \omega^{*} d \tau\right),
\end{aligned}
$$

which, by using (19), (21), and (23), can be written as follows:

$$
\begin{aligned}
\vartheta= & \frac{J L_{a}}{n k_{m}} \mu_{m}+\frac{1}{n k_{m}}\left(b L_{a}+J R_{a}\right)\left(\dot{\omega}+\frac{b}{J} \omega(0)-\frac{b^{2} L_{a}}{n J^{2} k_{e}} i_{a}(0)\right) \\
& +\left(\frac{b R_{a}}{n k_{m}}+n k_{e}\right)\left(\omega-\omega(0)+\frac{b L_{a}}{n J k_{e}} i_{a}(0)\right), \\
\mu_{m}= & \ddot{\omega}^{*}(t)-\gamma_{2}\left(\dot{\omega}+\frac{b}{J} \omega(0)-\frac{b^{2} L_{a}}{n J^{2} k_{e}} i_{a}(0)-\dot{\omega}^{*}\right) \\
& -\gamma_{1}\left(\omega-\omega(0)+\frac{b L_{a}}{n J k_{e}} i_{a}(0)-\omega^{*}\right) \\
& -\gamma_{0}\left(\int_{0}^{t} \omega d \tau-\frac{L_{a}}{n k_{e}} i_{a}(0)-\int_{0}^{t} \omega^{*} d \tau\right) .
\end{aligned}
$$

Substituting (26) into (11), and recalling that $F_{1}=\omega$, and deriving once with respect to time (15), is obtained so that the tuning rule that follows such expression is still valid. In summary, the proposed controller is made by (25), along with (20), (22), and (24). Note that this controller is implemented by both armature current and armature voltage measurements, so that there is not any mechanic variable measured; that is, neither velocity nor acceleration angular measurements are required.

2.2. An Average Controller Design for the Buck Converter. This subsection presents a control based on differential flatness for the Buck converter, which must be able to provide a voltage profile $\vartheta$ which is given by the motor control.

Converter switched dynamics is given by [22]:

$$
\begin{aligned}
& L \frac{d i}{d t}=-v+E u, \\
& C \frac{d v}{d t}=i-\frac{v}{R},
\end{aligned}
$$

where $i$ represents the inductor current and $v$ is the output capacitor voltage. The control input, $u$, represents the switching position function, which is a discrete-valued signal taking values in the set $\{0,1\}$. The system parameters are constituted by $L$, which is the inductance of the input circuit; $C$, the capacitance of the output filter, and $R$, the output load resistance. The external voltage source has a constant value $E$. We assume that the circuit is in continuous conduction mode; that is, the average value of the inductor current never drops to zero, due to load variations.

The average converter model would be represented exactly by the same mathematical model (27), possibly by renaming the state variables with different symbols and by redefining the control variable $u$ as a sufficiently smooth function taking values in the compact interval of the real line $[0,1]$. In order to simplify the exposition, we will refer to model (27), with $u$ replaced by $u_{a v}$, as the average model, and it is used to obtain a suitable average controller, for the average (continuous) input variable $u_{a v}$. We shall however distinguish between the average control input, denoted by $u_{a v}$, and the switched control input, denoted by $u$.

The only feature that distinguishes the average model from the switched model will then be the control input. This will surely make things unequivocal.

The average model of the Buck converter is then described as follows:

$$
\begin{gathered}
\dot{x}=A x+B u_{a v} \\
y_{2}=C x
\end{gathered}
$$

where $x=\left(\begin{array}{ll}i & v\end{array}\right)^{T}$ and

$$
A=\left(\begin{array}{cc}
0 & -\frac{1}{L} \\
\frac{1}{C} & -\frac{1}{R C}
\end{array}\right) ; \quad B=\left(\begin{array}{c}
\frac{E}{L} \\
0
\end{array}\right) ; \quad C=\left(\begin{array}{l}
0 \\
1
\end{array}\right)^{T}
$$




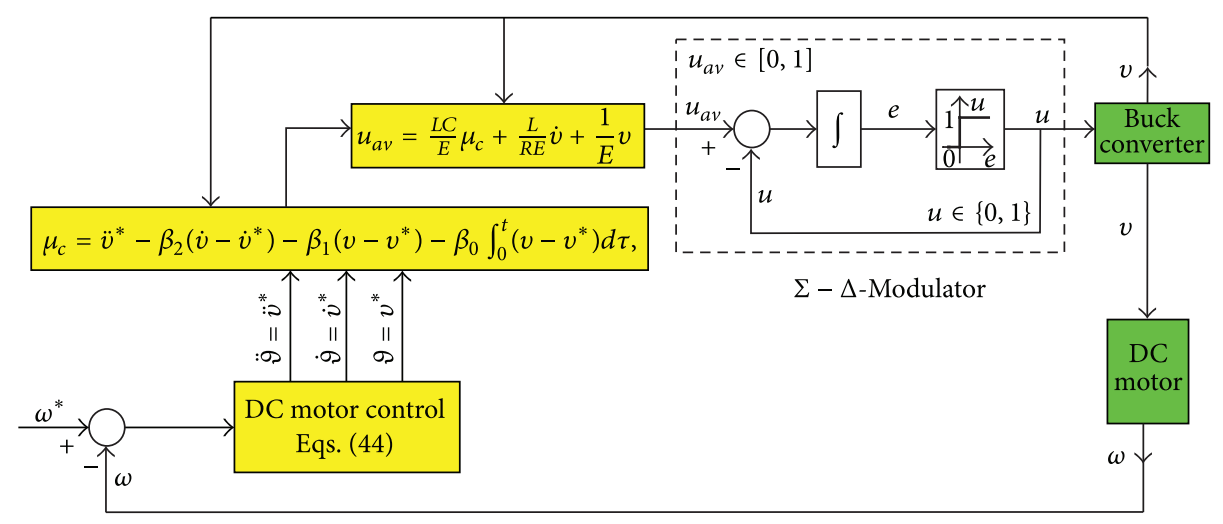

FIGURE 2: Simplified block diagram of the two-stage control implemented through a $\Sigma-\Delta$-modulator.

Controllability matrix of the system (28) is given by the following:

$$
\mathbf{C}_{2}=\left(\begin{array}{ll}
B & A B
\end{array}\right)=\left(\begin{array}{cc}
\frac{E}{L} & 0 \\
0 & \frac{E}{L C}
\end{array}\right) .
$$

Following a similar procedure which was presented for the motor, the flat output of the converter is determined by the following:

$$
F_{2}=\left(\begin{array}{ll}
0 & 1
\end{array}\right) \mathrm{C}_{2}^{-1} x=\frac{L C}{E} v
$$

Then, the voltage of the Buck power converter is considered as a flat output; that is,

$$
F_{2}=v
$$

By employing (28), a direct calculus shows that differential parametrization of the system in terms of $F_{2}$, is given by the following:

$$
\begin{gathered}
v=F_{2}, \\
i=C \dot{F}_{2}+\frac{1}{R} F_{2}, \\
u_{a v}=\frac{L C}{E} \ddot{F}_{2}+\frac{L}{R E} \dot{F}_{2}+\frac{1}{E} F_{2} .
\end{gathered}
$$

From (35) is evident that if the control converter is chosen as follows:

$$
u_{a v}=\frac{L C}{E} \mu_{c}+\frac{L}{R E} \dot{F}_{2}+\frac{1}{E} F_{2}
$$

then, the trajectory tracking problem of the converter output voltage is simplified to control the system:

$$
\ddot{F}_{2}=\mu_{c} \text {. }
$$

If $F_{2}^{*}$ is the desired output voltage of the converter, a choice of $\mu_{c}$ such that $F_{2} \rightarrow F_{2}^{*}$ when $t \rightarrow \infty$, is determined by the following:

$$
\mu_{c}=\ddot{F}_{2}^{*}-\beta_{2}\left[\dot{F}_{2}-\dot{F}_{2}^{*}\right]-\beta_{1}\left[F_{2}-F_{2}^{*}\right]-\beta_{0} \int_{0}^{t}\left[F_{2}-F_{2}^{*}\right] d \tau .
$$

In order to show that $\mu_{c}$ satisfies this task, (38) is substituted in (37) and its first derivative with respect to time is calculated. Furthermore, voltage tracking error is defined as $e=F_{2}-$ $F_{2}^{*}$, so that close-loop dynamic error is determined by the following:

$$
\dddot{e}+\beta_{2} \ddot{e}+\beta_{1} \dot{e}+\beta_{0} e=0,
$$

whose polynomial characteristic is as follows:

$$
p_{2}(s)=s^{3}+\beta_{2} s^{2}+\beta_{1} s+\beta_{0}
$$

In order to assure that $e \rightarrow 0$ when $t \rightarrow \infty$, it is proposed that $p_{2}(s)$ assumes the desired dynamic of the Hurwitz polynomial:

$$
p_{2 d}(s)=\left(s+a_{2}\right)\left(s^{2}+2 \zeta_{2} \omega_{n 2} s+\omega_{n 2}^{2}\right) .
$$

By making equal this polynomial (term by term) to the closeloop polynomial (40), it is found that controller gains are given by the following:

$\beta_{2}=a_{2}+2 \zeta_{2} \omega_{n 2} ; \quad \beta_{1}=2 \zeta_{2} \omega_{n 2} a_{2}+\omega_{n 2}^{2} ; \quad \beta_{0}=a_{2} \omega_{n 2}^{2}$.

2.3. Two-Stage Controller Implemented through a $\Sigma-\Delta$ Modulator. For the angular velocity trajectory tracking of $\omega^{*}$ based on energy provided from a Buck power converter for the DC motor, a two-stage control scheme is employed. Thus, it is required to have an integration of two controllers, one for the Buck power converter and another for a DC motor. A block diagram is shown in Figure 2.

Starting from a mathematical model of the DC motor given by the following:

$$
\begin{gathered}
L_{a} \frac{d i_{a}}{d t}=\vartheta-R_{a} i_{a}-n k_{e} \omega, \\
J \frac{d \omega}{d t}=-b \omega+n k_{m} i_{a} .
\end{gathered}
$$


It was found that control associated with a DC motor is given by the following:

$$
\begin{aligned}
\vartheta=\frac{J L_{a}}{n k_{m}} \mu_{m} & +\frac{1}{n k_{m}}\left(b L_{a}+J R_{a}\right) \widehat{\dot{\omega}}+\left(\frac{b R_{a}}{n k_{m}}+n k_{e}\right) \widehat{\omega} \\
\mu_{m}= & \ddot{\omega}^{*}(t)-\gamma_{2}\left(\widehat{\dot{\omega}}-\dot{\omega}^{*}\right)-\gamma_{1}\left(\widehat{\omega}-\omega^{*}\right) \\
& -\gamma_{0}\left(\widehat{\int_{0}^{t} \omega d \tau}-\int_{0}^{t} \omega^{*} d \tau\right)
\end{aligned}
$$

along with $\overline{\int_{0}^{t} \omega d} \tau, \widehat{\omega}$ and $\hat{\dot{\omega}}$ determined by (20), (22), and (24), respectively. Note that equation in (44) are constructed by using both armature current and armature voltage measurements.

For the Buck converter average model, which drives the DC motor, determined by the following:

$$
\begin{gathered}
L \frac{d i}{d t}=-v+E u_{a v}, \\
C \frac{d v}{d t}=i-\frac{v}{R},
\end{gathered}
$$

an average control $u_{a v}$ was obtained, given by (36) and (38), which is not a suitable signal for driving the switching power converter, so that we propose the use of the average control flatness-based (36)-(38) in sliding mode implementation using a $\Sigma-\Delta$-modulator, as discussed in $[21,22]$; that is,

$$
\begin{gathered}
u=\frac{1}{2}[1+\operatorname{sign} e], \\
\dot{e}=u_{a v}-u, \\
u_{a v}=\frac{L C}{E} \mu_{c}+\frac{L}{R E} \dot{v}+\frac{1}{E} v, \\
\mu_{c}=\ddot{v}^{*}-\beta_{2}\left(\dot{v}-\dot{v}^{*}\right)-\beta_{1}\left(v-v^{*}\right)-\beta_{0} \int_{0}^{t}\left(v-v^{*}\right) d \tau,
\end{gathered}
$$

being as

$$
v^{*}=\vartheta \text {. }
$$

So that, the desired voltage for the Buck converter $v^{*}$ is given by the voltage profile $\vartheta$, obtained by controlling the DC motor. This strategy allows an asymptotic trajectory tracking such that $\omega \rightarrow \omega^{*}$ when $t \rightarrow \infty$.

\section{Numerical Simulations}

In this section, numerical simulations show the Buck converter-DC motor system behavior in close-loop the control law (44) for the DC motor, along with the switching control implemented through a $\Sigma-\Delta$-modulator (46) for the converter.

The results found in this paper are applied for the case when a desired angular velocity trajectory is given by a sixthorder Bézier polynomial as follows:

$$
\omega^{*}(t)=\bar{\omega}\left(t_{i}\right)+\left[\bar{\omega}\left(t_{f}\right)-\bar{\omega}\left(t_{i}\right)\right] \varphi\left(t, t_{i}, t_{f}\right),
$$

being as $\varphi\left(t, t_{i}, t_{f}\right)$ a polynomial function that interpolates between 0 and 1 , defined by the following:

$$
\begin{aligned}
& \varphi\left(t, t_{i}, t_{f}\right) \\
& =\left\{\begin{array}{l}
0, \quad \text { for } t \leq t_{i}, \\
\left(\frac{t-t_{i}}{t_{f}-t_{i}}\right)^{3} \\
\times\left[20-45\left(\frac{t-t_{i}}{t_{f}-t_{i}}\right)+36\left(\frac{t-t_{i}}{t_{f}-t_{i}}\right)^{2}-10\left(\frac{t-t_{i}}{t_{f}-t_{i}}\right)^{3}\right], \\
1, \quad \text { for } t \geq t_{f},
\end{array}\right.
\end{aligned}
$$

where $t_{i}$ and $t_{f}$ are the initial and final time of the trajectory given, while $\bar{\omega}\left(t_{i}\right)$ and $\bar{\omega}\left(t_{f}\right)$ represent the transference angular velocity in equilibrium associated with $t_{i}$ and $t_{f}$.

For synthesis purposes, (48) was chosen such that $t_{i}=2 \mathrm{~s}$ and $t_{f}=4 \mathrm{~s}$, with $\bar{\omega}\left(t_{i}\right)=0.04 \mathrm{rad} / \mathrm{s}$ and $\bar{\omega}\left(t_{f}\right)=15 \mathrm{rad} / \mathrm{s}$. Thereby, $\vartheta(t)$ changes between $\bar{\vartheta}\left(t_{i}\right)=69.7 \mathrm{mV}$ and $\bar{\vartheta}\left(t_{f}\right)=$ $26.13 \mathrm{~V}$.

Numerical simulation includes the following nominal parameters for the mathematical model of the DC motor:

$$
\begin{gathered}
L_{a}=2.219 \times 10^{-3} \mathrm{H}, \quad R_{a}=0.965 \Omega, \quad n=14.5, \\
k_{e}=120.1 \times 10^{-3} \mathrm{~N}-\mathrm{m} / \mathrm{A}, \quad b=588 \times 10^{-6} \mathrm{~N} \cdot \mathrm{m} \cdot \mathrm{s}, \\
J=118.2 \times 10^{-3} \mathrm{~kg} \cdot \mathrm{m}^{2}, \quad k_{m}=120.1 \times 10^{-3} \mathrm{~V}-\mathrm{s} / \mathrm{rad} .
\end{gathered}
$$

These are the nominal parameters of the Buck converter used for the numerical simulations:

$$
L=4.94 \mathrm{mH}, \quad C=224.4 \mu \mathrm{F}, \quad R=28 \Omega, \quad E=36 \mathrm{~V} .
$$

The controller gains calculated for the DC motor are $\gamma_{2}, \gamma_{1}, \gamma_{0}$ and the converter controllers are $\beta_{2}, \beta_{1}, \beta_{0}$, they were selected according to th following:

$$
\begin{array}{lll}
a_{1}=23, & \zeta_{1}=0.907, & \omega_{n 1}=555, \\
a_{2}=175, & \zeta_{2}=0.707, & \omega_{n 2}=855 .
\end{array}
$$

In order to highlight the efficiency of the designed twostage controller, a rapid change of the converter load is performed, this is given by the following:

$$
R_{m}= \begin{cases}R & \text { for } 0 \leq t<2.5 \mathrm{~s} \\ 20 \% R=5.6 \Omega & \text { for } 2.5 \leq t<3.5 \mathrm{~s} \\ R & \text { for } 3.5 \leq t<4.5 \mathrm{~s} \\ 180 \% R=50.4 \Omega & \text { for } 4.5 \leq t<5.5 \mathrm{~s} \\ R & \text { for } t \geq 5.5 \mathrm{~s}\end{cases}
$$

The corresponding results are presented in Figure 3. It is clear that $\widehat{\omega}$ follows the nominal trajectory $\omega^{*}$; it shows the efficiency of the designed two-stage controller under uncertainties in the parameter $R$. 


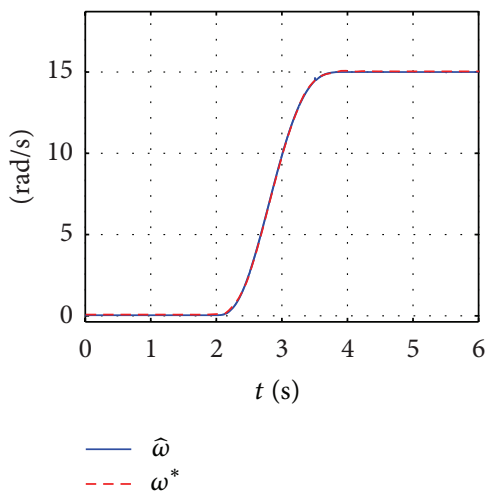

(a)

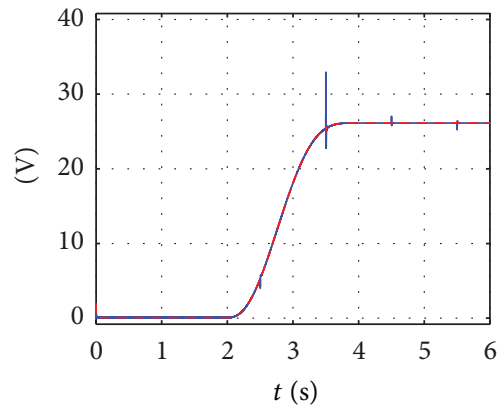

$-v$

(b)
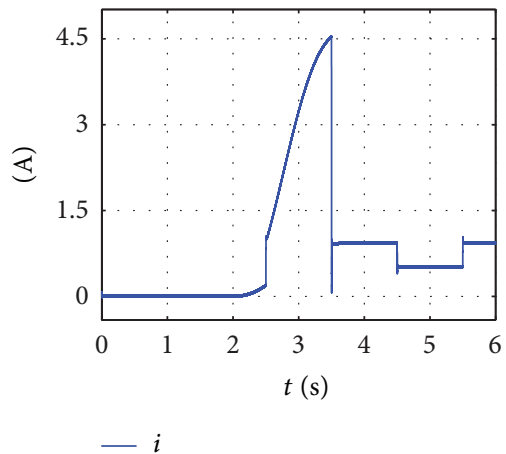

(c)

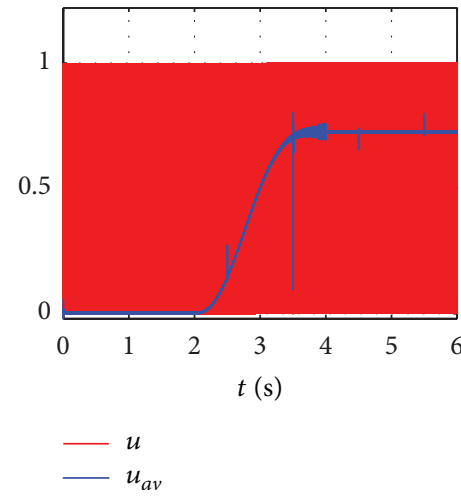

(d)

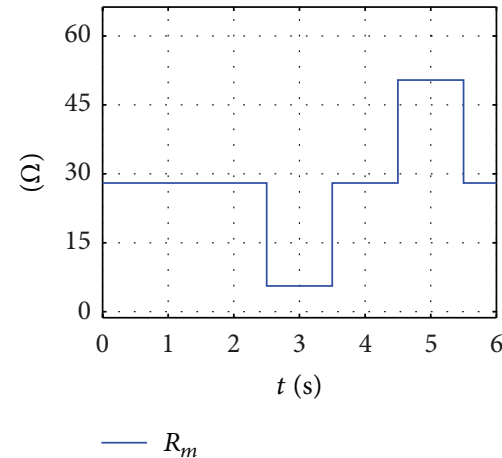

(e)

FIgURE 3: Numerical simulations for $R$ uncertainties.

In order to show that two-stage control approach presented for this application is robust with respect to the voltage source, the following changes of $E$ are proposed:

$$
E_{m}= \begin{cases}E & \text { for } 0 \leq t<2 \mathrm{~s} \\ 75 \% E=27 \mathrm{~V} & \text { for } 2 \leq t<3 \mathrm{~s} \\ E & \text { for } 3 \leq t<4 \mathrm{~s} \\ 125 \% E=45 \mathrm{~V} & \text { for } 4 \leq t<5 \mathrm{~s} \\ E & \text { for } t \geq 5 \mathrm{~s}\end{cases}
$$

Figure 4 shows the behavior of the mechanical and electrical variables in the system, when there are uncertainties of $E$ value, it can be observed that the trajectory tracking is successfully performed, since $\widehat{\omega} \rightarrow \omega^{*}$ when only both the voltage $\vartheta$ and the armature current $i_{a}$ are measured.

Figure 5 shows how the desired trajectory (48) is followed properly although rapid changes in $C$ are introduced. In this simulations these changes are defined by the following:

$$
C_{m}= \begin{cases}C & \text { for } 0 \leq t<2.5 \mathrm{~s} \\ 900 \% C=2019.6 \mu \mathrm{F} & \text { for } 2.5 \leq t<3 \mathrm{~s} \\ C & \text { for } 3 \leq t<4 \mathrm{~s} \\ 10 \% C=22.44 \mu \mathrm{F} & \text { for } 4 \leq t<4.5 \mathrm{~s} \\ C & \text { for } t \geq 4.5 \mathrm{~s}\end{cases}
$$

Figure 6 shows the system behavior when rapid changes of $L$ are given by the following:

$$
L_{m}= \begin{cases}L & \text { for } 0 \leq t<2.5 \mathrm{~s}, \\ 900 \% L=44.46 \mathrm{mH} & \text { for } 2.5 \leq t<3.5 \mathrm{~s}, \\ 10 \% L=0.494 \mathrm{mH} & \text { for } 3.5 \leq t<4.5 \mathrm{~s}, \\ L & \text { for } t \geq 4.5 \mathrm{~s} .\end{cases}
$$

Figure 7 presents the results obtained when the motor inertia changes are given by the following:

$$
J_{m}= \begin{cases}J & \text { for } 0 \leq t<4 \mathrm{~s} \\ 500 \% J & \text { for } 4 \leq t<4.5 \mathrm{~s} \\ J & \text { for } 4.5 \leq t<5 \mathrm{~s} \\ 1500 \% J & \text { for } 5 \leq t<5.5 \mathrm{~s} \\ J & \text { for } t \geq 5.5 \mathrm{~s} .\end{cases}
$$

Finally, numerical simulations are presented when the viscous friction coefficient is changed abruptly. Result are shown in Figure 8 when the uncertainties are proposed as follows:

$$
b_{m}= \begin{cases}b & \text { for } 0 \leq t<2 \mathrm{~s} \\ 150 \% b & \text { for } 2 \leq t<2.5 \mathrm{~s}, \\ b & \text { for } 2.5 \leq t<3.5 \mathrm{~s} \\ 300 \% b & \text { for } 3.5 \leq t<4 \mathrm{~s} \\ b & \text { for } t \geq 4 \mathrm{~s}\end{cases}
$$



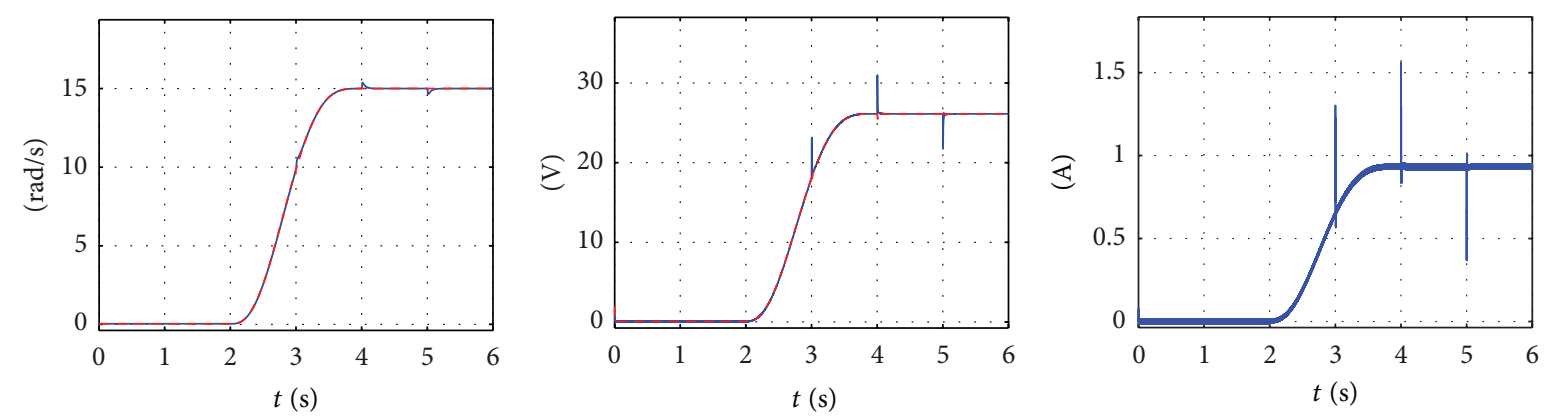

$\widehat{\omega}$
$--\omega^{*}$

$-v$
$--\vartheta$

(a)

(b)

(c)

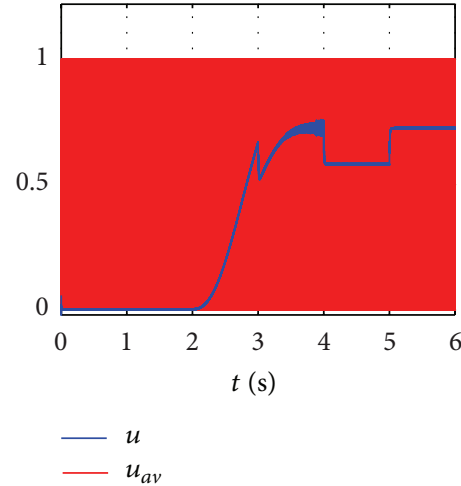

(d)

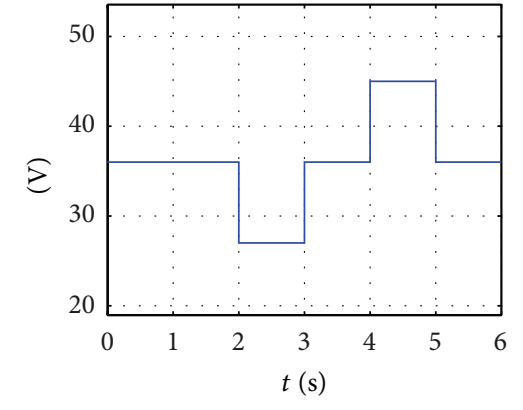

$-E_{m}$

FIGURE 4: Numerical simulations for power-supply uncertainties.

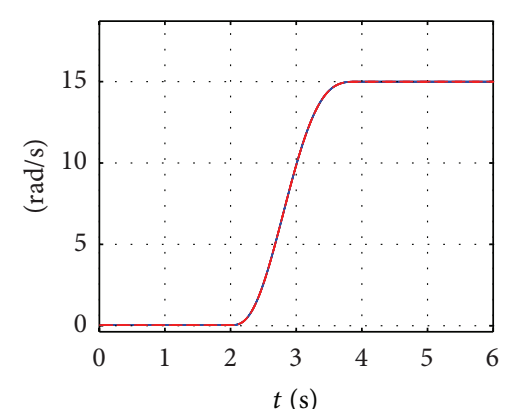

$-\widehat{\omega}$

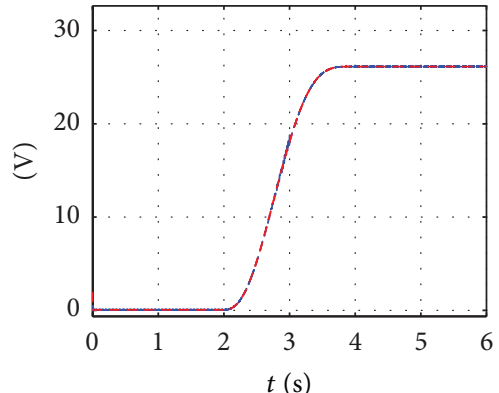

$-v$

(b)

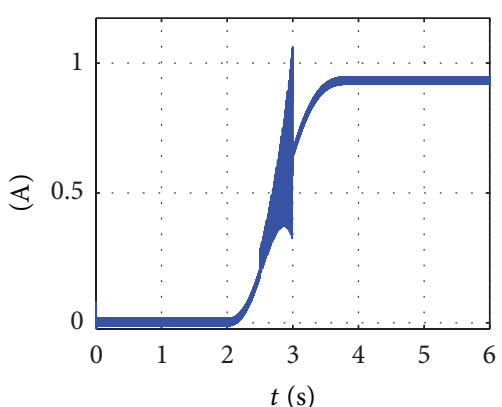

$-i$ (a)

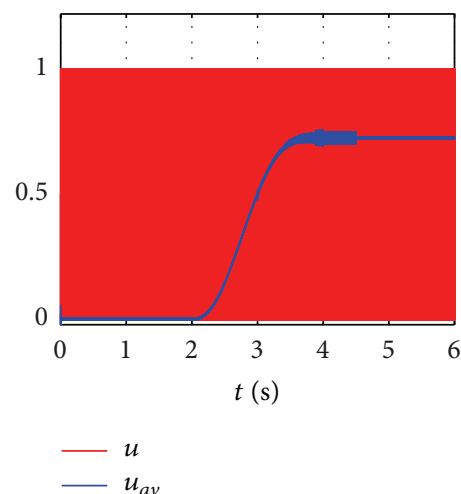

(d)

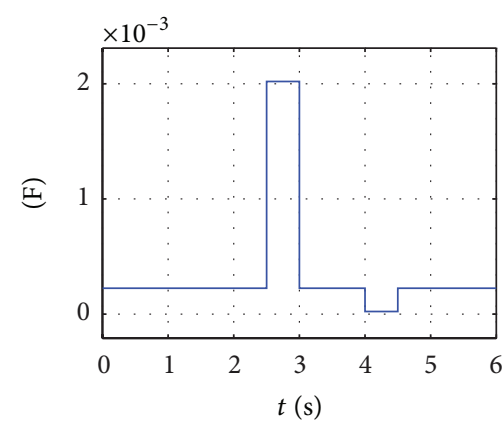

$-C_{m}$

FIgURE 5: Numerical simulations for $C$ abrupt changes. 


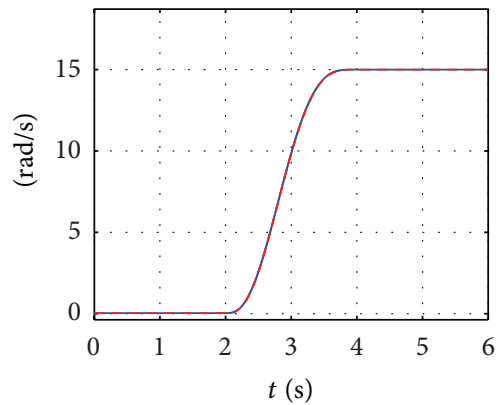

$\widehat{\omega}$
$--\omega^{*}$

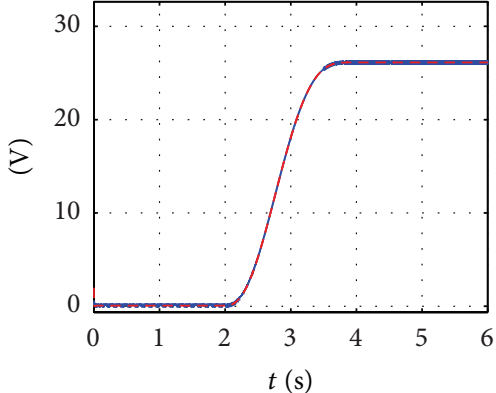

$-v$
$--\vartheta$ (a)

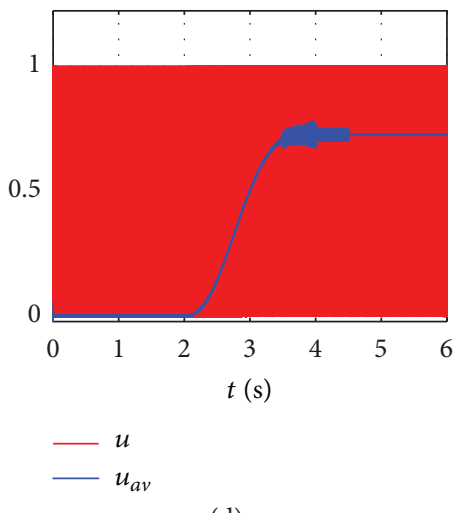

(b)
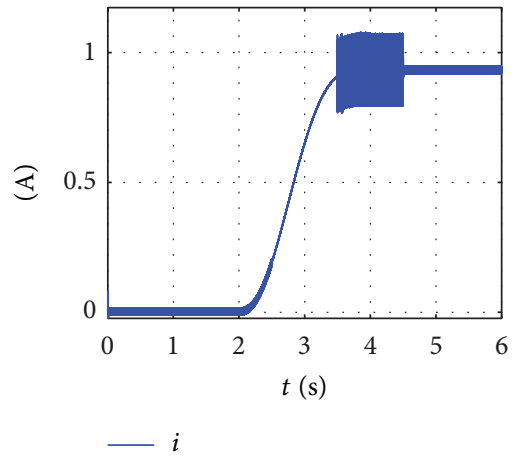

(c)

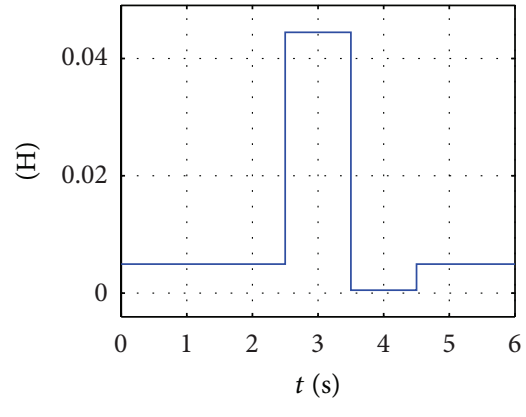

$-L_{m}$

(e)

Figure 6: Numerical simulations for $L$ changes.

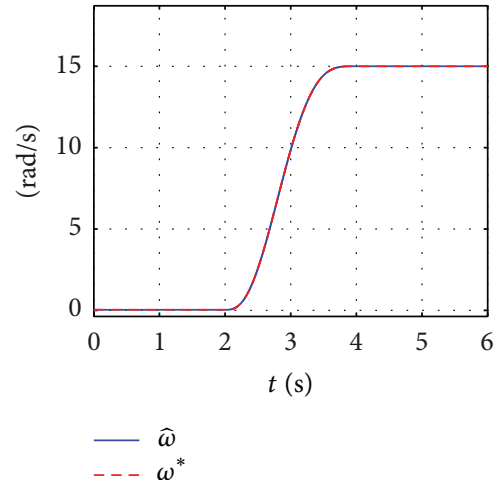

(a)

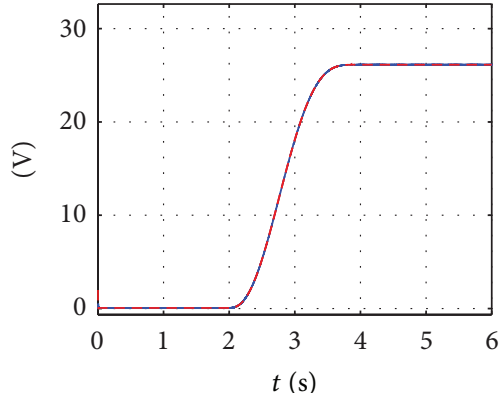

$-v$

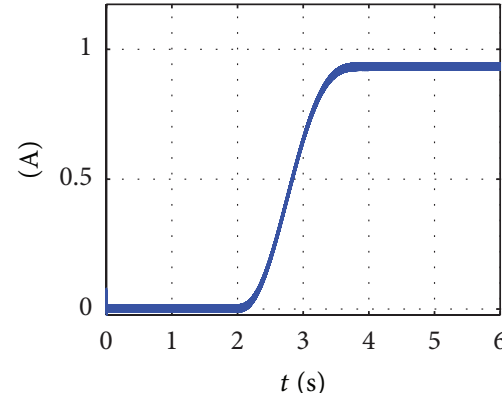

$-i$ (b)

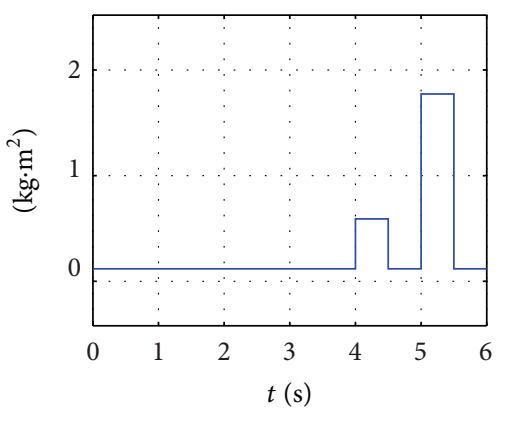

(e)
$-J_{m}$

(c)

(d)

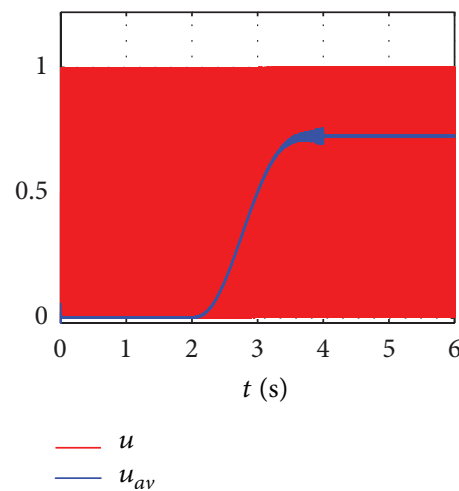

FiguRE 7: Numerical simulations for $J$ uncertainties. 


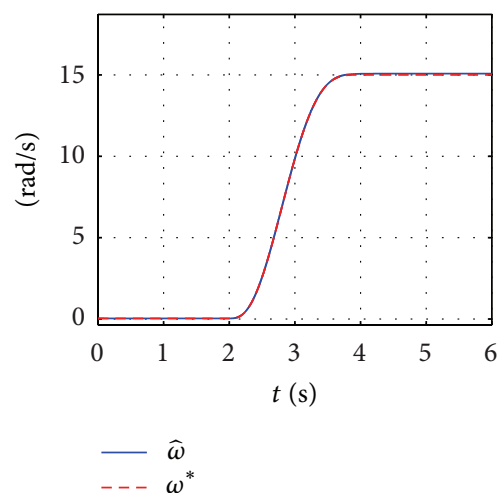

(a)

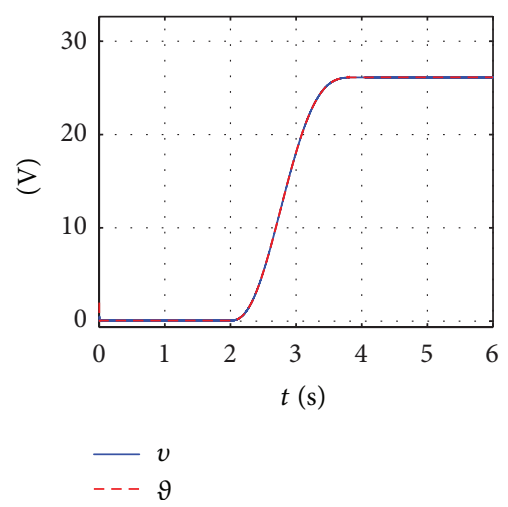

(b)

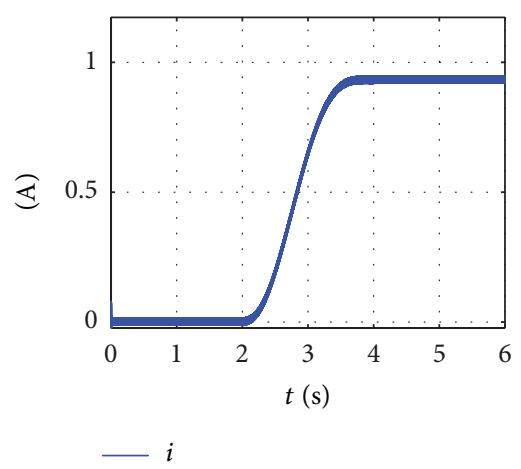

(c)

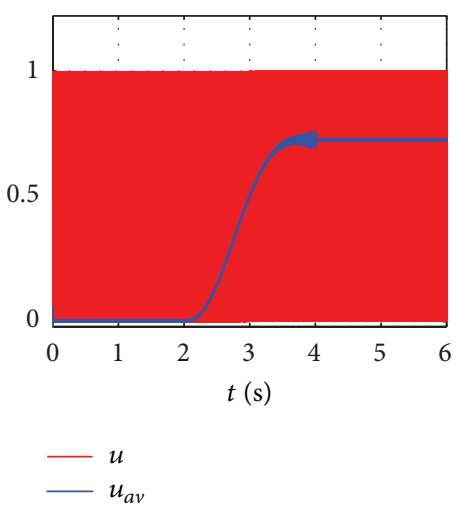

(d)

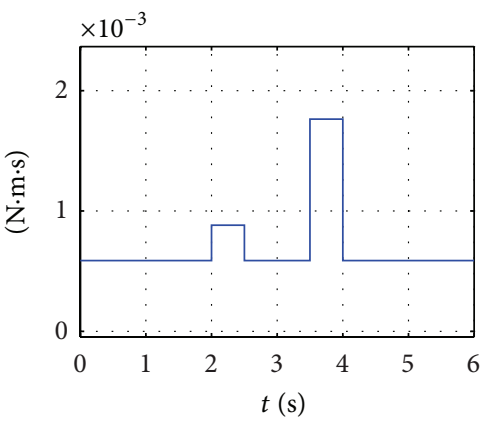

$-b_{m}$

Figure 8: Numerical simulations for $b$ uncertainties.

\section{Conclusions}

This paper presented a solution for the angular velocity trajectory tracking task of a DC motor driven by a DC/DC Buck power converter through a two-stage control based on sliding mode implementation using a $\Sigma-\Delta$-modulator, without velocity measurements. This controller is composed of two stages; one controller is linked to the DC motor and another controller to the Buck converter, where both controllers are interconnected, more specific details are as follows.

(1) The first-stage controller is based on differential flatness and integral reconstructors, for the DC motor, which determines the profile $\vartheta$ such that $\widehat{\omega} \rightarrow \omega^{*}$. An important feature of this approach is related to the fact that the controller requires neither angular velocity acquisition, nor acceleration nor position. This approach requires only armature voltage and armature current of the DC motor. However, angular velocity converges exponentially to the desired velocity trajectory.

(2) The second-stage controller is an average control based on differential flatness which achieves that $v \rightarrow \vartheta$. Due to the fact that average control is not suitable for the switching converter, in this paper, we have shown via simulations that the use of classical $\Sigma-\Delta$-modulator can solve the sliding mode control implementation problem arising from the average feedback controller designing a rather efficient manner. This approach retains, in an average sense, the desirable features of the designed average feedback controller [21, 22].

(3) A two-stage control was presented via the integration of the controllers aforementioned along with a $\Sigma-\Delta$ modulator, according to Figure 2.

The control goal was successfully achieved since the motor angular velocity converges to the desired angular velocity. Furthermore, this controller has been validated against parametric uncertainties related to load converter $R$, system power source $E$, capacitance $C$, and inductance $L$, as well as inertia $J$ and viscous friction coefficient $b$. It is important to underline that neither this kind of abrupt changes nor large changes happen in practice simultaneously, with respect to their nominal values, like the results presented in this paper. However, these simulations were made in order to show the performance and robustness achieved of this approach which is suitable for practical applications. As a future work, this technique is worthwhile to be evaluated experimentally.

\section{Acknowledgments}

R. Silva-Ortigoza, M. Marcelino-Aranda, and H. Taud acknowledge financial support from SNI-México, Secretaría de Investigación y Posgrado del Instituto Politécnico 
Nacional (SIP-IPN), and the Programs EDI, EDD, and COFAA of IPN. V. M. Hernández-Guzmán and R. BautistaQuintero thank the SNI-México for financial support.

\section{References}

[1] N. Mohan, T. M. Undeland, and W. P. Robbins, Power Electronics: Converters, Applications, and Design, John Wiley \& Sons, 2003.

[2] S. E. Lyshevski, Electromechanical Systems, Electric Machines and Applied Mechatronics, CRC Press, 2000.

[3] J. Linares-Flores and H. Sira-Ramírez, "A smooth starter for a DC machine: a flatness based approach," in Proceedings of the 1st International Conference on Electrical and Electronics Engineering (ICEEE '04), pp. 589-594, September 2004.

[4] J. Linares-Flores and H. Sira-Ramírez, "Sliding mode-delta modulation GPI control of a DC motor through a Buck converter," in Proceedings of 2nd IFAC Symposium on System, Structure and Control, pp. 405-409, Oaxaca, Mexico, December 2004.

[5] J. Linares-Flores and H. Sira-Ramírez, "DC motor velocity control through a DC-to-DC power converter," in Proceedings of the 43rd IEEE Conference on Decision and Control (CDC '04), pp. 5297-5302, Atlantis, Paradise Island, Bahamas, December 2004.

[6] H. El Fadil and F. Giri, "Accounting of Dc-Dc power converter dynamics in DC motor velocity adaptive control," in Proceedings of the IEEE International Conference on Control Applications (CCA '06), pp. 3157-3162, Munich, Germany, October 2006.

[7] R. Ortega, A. Loria, P. J. Nicklasson, and H. Sira-Ramírez, Passivity-Based Control of Euler-Lagrange Systems, Springer, 1998.

[8] J. Linares-Flores, Control suave de velocidad de motores de cd mediante convertidores de potencia $c d / c d$ [Ph.D. thesis], Sección de Mecatrónica del Departamento de Ingeniería Eléctrica del CINVESTAV-IPN, 2006.

[9] J. Linares-Flores, A. Orantes-Molina, and A. Antonio-García, "Arranque suave para un motor de CD a través de un convertidor reductor CD-CD," Ingeniería Investigación y Tecnología, vol. 12, no. 2, pp. 137-148, 2011.

[10] F. Antritter, P. Maurer, and J. Reger, "Flatness based control of a buck-converter driven DC motor," in Proceedings of the 4th IFAC Symposium on Mechatronic Systems (MX '06), pp. 36-41, Heidelberg, Germany, September 2006.

[11] M. A. Ahmad, R. M. T. Raja Ismail, and M. S. Ramli, "Control strategy of Buck converter driven DC motor: a comparative assessment," Australian Journal of Basic and Applied Sciences, vol. 4, no. 10, pp. 4893-4903, 2010.

[12] R. Sureshkumar and S. Ganeshkumar, "Comparative study of proportional integral and backstepping controller for buck converter," in Proceedings of the International Conference on Emerging Trends in Electrical and Computer Technology (ICETECT '11), pp. 375-379, Tamil Nadu, India, March 2011.

[13] H. Sira-Ramírez and M. A. Oliver-Salazar, "On the robust control of Buck-converter DC-motor combinations," IEEE Transactions on Power Electronics, vol. 28, no. 8, pp. 3912-3922, 2013.

[14] J. Linares-Flores, H. Sira-Ramírez, J. Reger, and R. SilvaOrtigoza, "An exact tracking error dynamics passive output feedback controller for a Buck-Boost-converter driven DC motor," in Proceedings of the 10th IEEE International Power Electronics Congress (CIEP '06), pp. 3-7, Cholula, Puebla, Mexico, October 2006.

[15] J. Linares-Flores, J. Reger, and H. Sira-Ramírez, "Load torque estimation and passivity-based control of a boostconverter/DC-motor combination," IEEE Transactions on Control Systems Technology, vol. 18, no. 6, pp. 1398-1405, 2010.

[16] A. W. Divelbiss and J. T. Wen, "Trajectory tracking control of a car-trailer system," Transactions on Control Systems Technology, vol. 5, no. 3, pp. 269-278, 1997.

[17] R. Silva-Ortigoza, G. Silva-Ortigoza, V. M. HernándezGuzmán, V. R. Barrientos-Sotelo, J. M. Albarrán-Jiménez, and V. M. Silva-García, "Trajectory tracking in a mobile robot without using velocity measurements for control of wheels," IEEE Latin America Transactions, vol. 6, no. 7, pp. 598-607, 2008.

[18] R. Silva-Ortigoza, M. Marcelino-Aranda, G. Silva-Ortigoza et al., "Wheeled Mobile Robots: a review," IEEE Latin America Transactions, vol. 10, no. 6, pp. 2209-2217, 2012.

[19] M. Fliess, R. Marquez, and E. Delaleau, "State feedbacks without asymptotic observers and generalized PID regulators," in Nonlinear Control in the Year 2000, A. Isidori, F. LamnabhiLagarrigue, and W. Respondek, Eds., vol. 258 of Lecture Notes in Control and Information Sciences, pp. 367-384, Springer, London, UK, 2001.

[20] M. Fliess, R. Marquez, E. Delaleau, and H. Sira-Ramírez, "Correcteurs proportionnels-intégraux généralisés," ESAIM Control, Optimisation and Calculus of Variations, no. 7, pp. 23-41, 2002.

[21] H. Sira-Ramírez and R. Silva-Ortigoza, "Sliding mode $\Sigma-\Delta$ modulation control of the boost converter," Asian Journal of Control, vol. 7, no. 4, pp. 349-355, 2005.

[22] H. Sira-Ramírez and R. Silva-Ortigoza, Control Design Techniques in Power Electronics Devices, Springer, London, UK, 2006.

[23] M. Fliess, J. Lévine, P. Martin, and P. Rouchon, "Flatness and defect of non-linear systems: introductory theory and examples," International Journal of Control, vol. 61, no. 6, pp. 1327-1361, 1995.

[24] H. Sira-Ramírez and S. K. Agrawal, Differentially Flat Systems, Marcel Dekker, 2004.

[25] V. M. Hernández-Guzmán, Control PI generalizado de sistemas no lineales [Ph.D. thesis], Sección de Mecatrónica del Departamento de Ingeniería Eléctrica del CINVESTAV-IPN, 2003. 


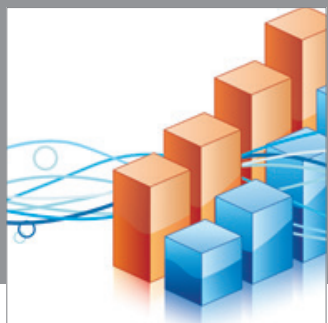

Advances in

Operations Research

mansans

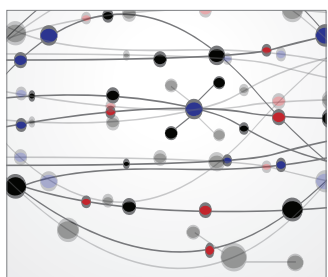

The Scientific World Journal
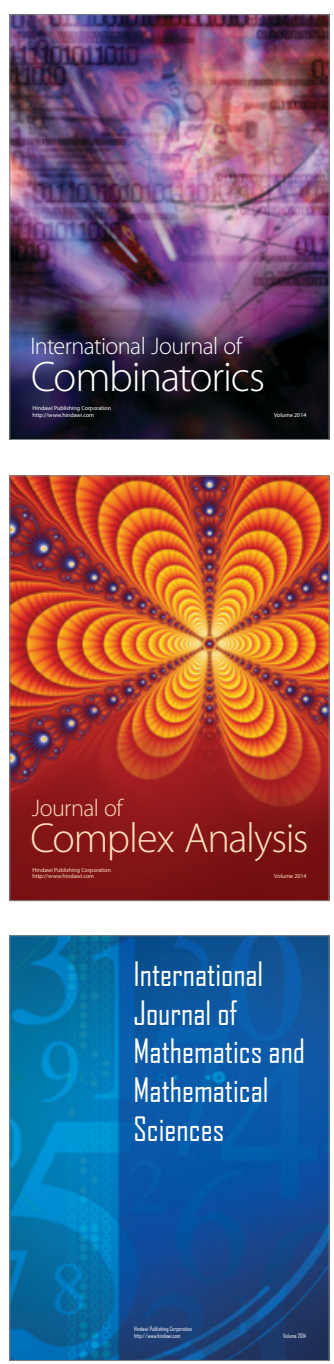
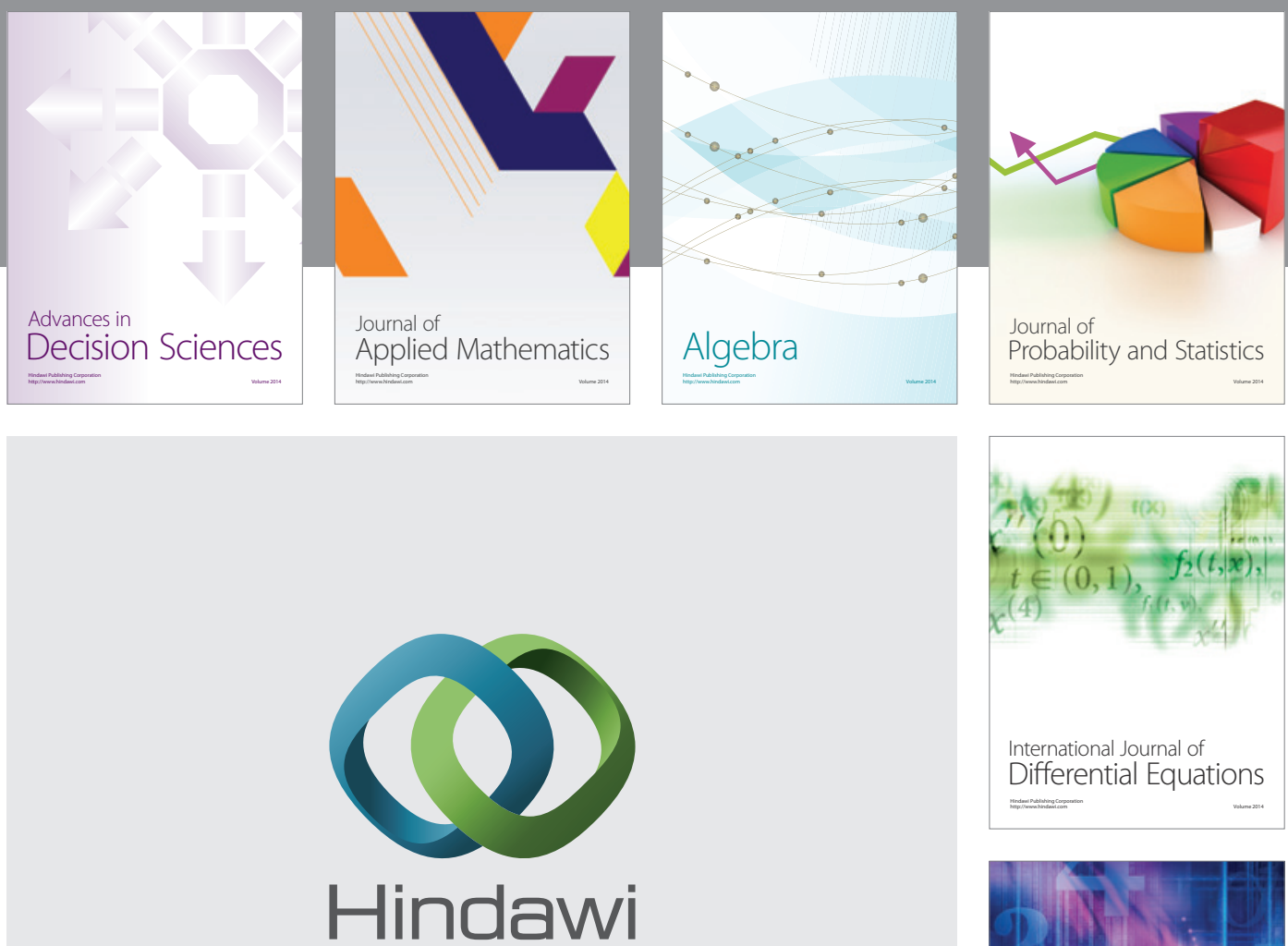

Submit your manuscripts at http://www.hindawi.com
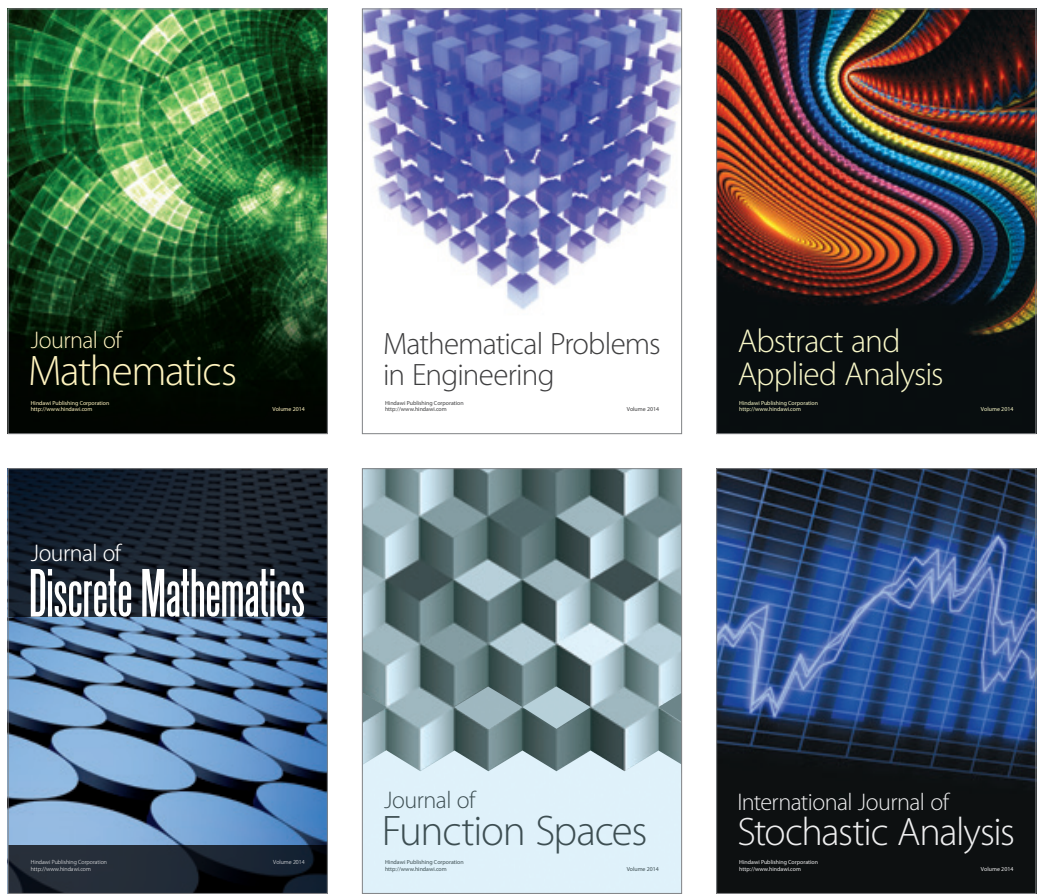

Journal of

Function Spaces

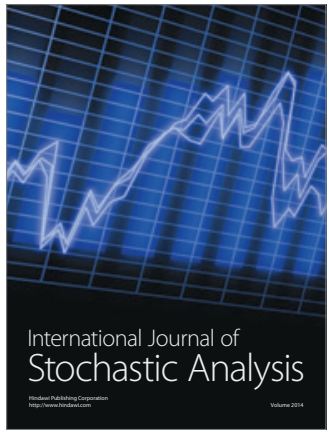

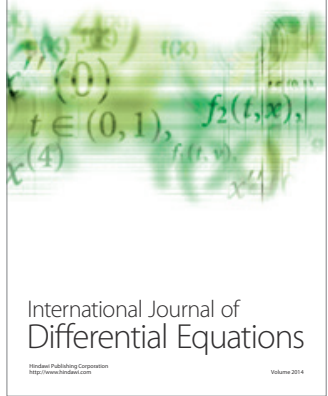
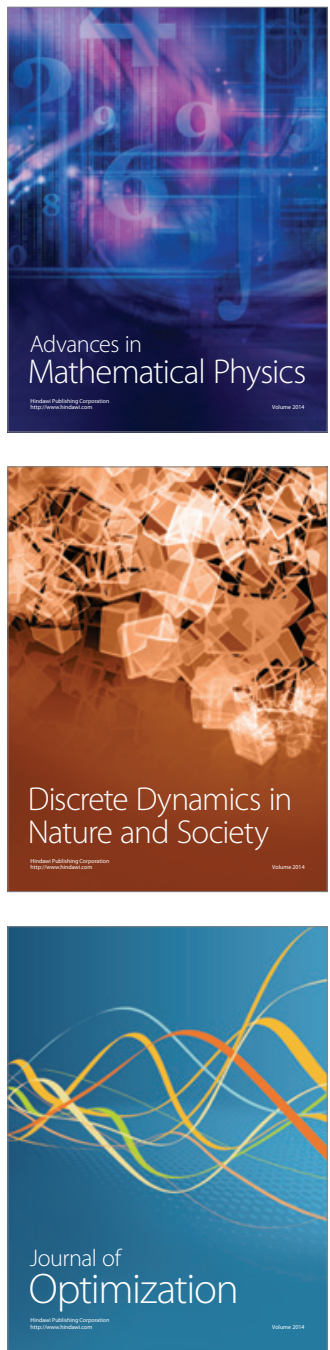